\title{
Masking Ability of Zirconia with and without Veneering Porcelain
}

\author{
Yeon-Jo Choi, DMD, MS ${ }^{1} \&$ Michael E. Razzoog, DDS, MS, MPH² \\ ${ }^{1}$ Clinical Assistant Professor, Department of Dentistry, Korea University Medical Center, Seoul, South Korea; Former graduate student, \\ Department of Prosthodontics, School of Dentistry, University of Michigan, Ann Arbor, MI \\ ${ }^{2}$ Professor and Director, Department of Prosthodontics, School of Dentistry, University of Michigan, Ann Arbor, MI
}

\begin{abstract}
Keywords
All-ceramic restoration; zirconium oxide; masking ability; color coordinates; total color difference.
\end{abstract}

\section{Correspondence}

Michael E. Razzoog, Department of Prosthodontics, School of Dentistry, University of Michigan, Ann Arbor, MI, 48109. E-mail: merim@umich.edu

The authors deny any conflicts of interest.

Accepted May 21, 2012

doi: 10.1111/j.1532-849X.2012.00915.x

\begin{abstract}
Purpose: The present study compared changes in CIE $\mathrm{L}^{*} \mathrm{a}^{*} \mathrm{~b}^{*}$ color coordinates of substrates of different colors when covered with zirconium oxide discs (Procera) and with such discs if veneered with two shades of porcelain.

Material and Methods: Forty background substrates were fabricated and divided into four groups depending on the color of the substrates: white, black, gray, and toothcolored (Vita shade A3). The initial color of the substrates was measured using a colorimeter. The color of the substrates covered with plain zirconium oxide discs and with zirconium oxide discs veneered with porcelains of two shades (Vita shade A1 and B4) was measured. The color difference between the substrates, the substrates covered with plain discs, and the substrates covered with veneered discs was calculated, and the data were statistically analyzed with one-way ANOVA and multiple paired $t$-test. Results: For each group of substrates, the resulting colors were significantly different when the substrates were covered by either plain zirconium oxide discs or zirconium oxide discs veneered with Vita shade A1 or B4 porcelain.

Conclusion: While zirconium oxide coping material alone has a degree of masking ability, the resulting color of a restoration can be further modified with the veneering porcelain.
\end{abstract}

Over the last 30 years metal ceramic crowns have been the most widely used restorations in fixed prosthodontics because of their strength and predictability; however, the esthetic outcome of such crowns is often compromised by the metal coping, which results in high value and excessive opacity at the cervical third and the dark appearance of overlying gingival tissues. All-ceramic crowns set a standard in esthetics because of the absence of underlying metal and the increased light transmission through the restorations. ${ }^{1}$ Numerous coping materials for all-ceramic restorations have been introduced to dentistry, and zirconium oxide is currently the most widely used coping material due to its high flexural strength and fracture resistance. ${ }^{2-4}$ To be clinically successful, zirconium oxide should fulfill several criteria. One of these is esthetics, which is often the major concern of clinicians and patients and is the principal driving force behind the rapid expansion in tooth-colored esthetic materials. A number of variables are involved in achieving the lifelike appearance of the restoration, among which is the ability of effectively masking an underlying core or discolored tooth structure.
The most widely used colorimetry system in dental research is the CIE $\mathrm{L}^{*} \mathrm{a}^{*} \mathrm{~b}^{*}$ system. In this system, the location of a particular shade in the color space is defined by three coordinates: $\mathrm{L}^{*}, \mathrm{a}^{*}$, and $\mathrm{b}^{*}$. The $\mathrm{L}$ coordinate represents the lightness of an object. The $\mathrm{a}^{*}$ coordinate corresponds to the chromaticity on the red/green axis and $b^{*}$ on the yellow/blue axis. Measurement of the total color difference between two objects, or in the same object before and after it is subjected to particular conditions, is described by $\Delta \mathrm{E}$. While indicative of a color difference, the magnitude of $\Delta \mathrm{E}$ gives no information of the character of the color of an object because it does not indicate the quantity and direction of the CIE $\mathrm{L}^{*} \mathrm{a}^{*} \mathrm{~b}^{*}$ components. ${ }^{5}$ Perceptibility is the detection of color difference between compared objects by the human eye, and acceptability is the color difference considered to be acceptable in shade match. A number of studies have suggested different perceptible and acceptable limits for $\Delta \mathrm{E}$ units. ${ }^{6-10}$ Vichi et al proposed three intervals for distinguishing color differences. ${ }^{6}$ Douglas et al reported 2.6 and 5.5 $\Delta \mathrm{E}$ units as perceptible and acceptable limits, ${ }^{7}$ but Lindsey and Wee reported that no differences between perceptible and 
acceptable limits were found in their study. ${ }^{8}$ The reported limits of $\Delta \mathrm{E}$ units vary widely and depend on individual observer and visual conditions such as illuminant, object, viewing distance, and optical geometry. ${ }^{11}$ Some authors have reported that the clinically acceptable limits of $\Delta \mathrm{E}$ units were $2.6,3.3$, and 3.7. ${ }^{12-14}$ Others proposed different $\Delta \mathrm{E}$ units as clinically acceptable limits in their studies. ${ }^{15,16}$ Despite much effort, the identification of a $\Delta \mathrm{E}$ unit for the visual perception of color difference is a very difficult task, and the establishment of a widely accepted limit is still controversial. ${ }^{17}$

Several studies have evaluated the masking ability or the translucency of various ceramic coping materials. ${ }^{18-26}$ However, few investigations have been performed on the masking ability of zirconium oxide as a coping material with and without veneering porcelain. ${ }^{25,26}$ Therefore, the present in vitro study was undertaken to evaluate colorimetrically the ability of zirconium oxide discs to mask the underlying substrates of four colors, the resulting colors of the substrates when the discs were veneered with porcelains of two shades, and the difference of the resulting colors of the substrates depending on the shade of veneering porcelain.

The following null hypotheses were tested:

(1) There will be no statistically significant difference between the initial color of substrates and the color of substrates covered with plain zirconium oxide discs.

(2) There will be no statistically significant difference between the color of substrates covered with plain zirconium oxide discs and the color of substrates covered with veneered zirconium oxide discs.

(3) There will be no statistically significant difference between the color of substrates covered with zirconium oxide discs veneered with shade A1 porcelain and the color of substrates covered with zirconium oxide discs veneered with shade B4 porcelain.

\section{Materials and methods}

A machined aluminum master index was used for the fabrication of multiple substrates. Both white and black substrates were machined from delrin (chemistry shop of University of Michigan, Ann Arbor, MI). Gray substrates were prepared by mixing autopolymerizing acrylic resin (Jet, Lang Dental, Wheeling, IL) with amalgam powder and pouring it into the impressions of the master die. The ratio of the amalgam was recorded so that consistent mixtures of the substrate resin could be fabricated. Tooth-colored substrates were fabricated from autopolymerizing acrylic resin (Jet), shade A3. Forty substrates were fabricated and divided into four groups depending on the color of substrates. Each group consisted of 10 substrates.

Forty zirconium oxide discs, each $10.0 \mathrm{~mm}$ in diameter and $0.4 \mathrm{~mm}$ in thickness, were fabricated and statistically analyzed for identical dimension and color with the Shapiro-Wilk normality test and one-sample $t$-test by Procera ${ }^{\circledR}$ (Nobel Biocare, Goteborg, Sweden) and were used for the experiment. A power calculation was run on results from a previous study using alumina copings to determine the number of specimens needed to achieve an $80 \%$ power. Ten specimens of each of the groups exceeded the requirements. Before the test, each disk was measured in three locations with a Digimatic Caliper (Mitutoyo Corp, Tokyo, Japan) to determine the actual thickness.

A colorimeter (Minolta Chroma Meter II, Minolta Inc., Osaka, Japan) was used for all color measurements. The colorimeter has a $3 \mathrm{~mm}$ head and a diffuse illumination vertical viewing $\left(0^{\circ}\right)$ geometry for color measurement. CIE L*a* $b^{*}$ notations were used, and the standard illuminant D65 was selected for all measurements. Prior to each experimental measurement, the colorimeter was calibrated to a white standard tile supplied by the manufacturer. ${ }^{27}$

First, the measuring head of the colorimeter was placed onto the center of top surface of each substrate, and the $\mathrm{L}^{*} \mathrm{a}^{*} \mathrm{~b}^{*}$ color notation was measured three times consecutively. An average of the three readings was calculated to give the initial color of the substrate. Prior to the veneering, each of the 40 plain zirconium oxide discs was placed over each of the 40 substrates without a cement layer in random pairings, and the same measuring procedures were repeated.

Ten discs paired with black substrates were veneered with shade A1 porcelain, and another 10 discs paired with white substrates were veneered with shade B4 porcelain (Vita D, Vita, Bad Sackingen, Germany). The other remaining 20 plain discs were left unused. These shades were chosen to represent a possible extreme of shade selection relative to opacifiers in the porcelain. The initial thickness of the veneering layer was slightly more than $0.4 \mathrm{~mm}$; the excess was ground with a diamond bur to achieve a uniform thickness of $0.4 \mathrm{~mm}$. All veneered surfaces were polished with 600 -grit polishing paper (Ecomet 3, Buehler Ltd, Lake Bluff, IL) to produce a smooth surface, which was microscopically examined to ensure lack of porosity. The final thickness of the veneer portion was verified to be $0.4 \mathrm{~mm}$ with a Digimatic Caliper. Finally, all 20 discs were self-glazed at $910^{\circ} \mathrm{C}$.

Ten discs veneered with shade A1 porcelain were placed over 10 substrates of each group without a cement layer in random pairings, and the color measurements were repeated. Again, another 10 discs veneered with shade B4 porcelain were placed over 10 substrates of each group without a cement layer in random pairings, and the color measurements were then completed (Fig 1).

For each of the 40 substrates used in the present study, the color differences between four variances were calculated as follows:

(1) The substrate (S) and the same substrate covered with a plain disc $(\mathrm{S}+\mathrm{D})$ : $\mathrm{S}-(\mathrm{S}+\mathrm{D})$.

(2) The substrate $(S)$ and the same substrate covered with a disc veneered with Vita shade $A 1$ porcelain $(S+D+A 1)$ : $\mathrm{S}-(\mathrm{S}+\mathrm{D}+\mathrm{A} 1)$.

(3) The substrate (S) and the same substrate covered with a disc veneered with Vita shade B4 porcelain $(S+D+B 4)$ : $\mathrm{S}-(\mathrm{S}+\mathrm{D}+\mathrm{B} 4)$.

(4) The substrate $(\mathrm{S}+\mathrm{D})$ covered with a plain disc and the same substrate covered with a disc veneered with Vita shade $\mathrm{A} 1$ porcelain $(\mathrm{S}+\mathrm{D}+\mathrm{A} 1)$ : $(\mathrm{S}+\mathrm{D})-(\mathrm{S}+\mathrm{D}+\mathrm{A} 1)$.

(5) The substrate covered with a plain disc $(\mathrm{S}+\mathrm{D})$ and the same substrate covered with a disc veneered with Vita shade B4 porcelain $(\mathrm{S}+\mathrm{D}+\mathrm{B} 4)$ : $(\mathrm{S}+\mathrm{D})-(\mathrm{S}+\mathrm{D}+\mathrm{B} 4)$. 


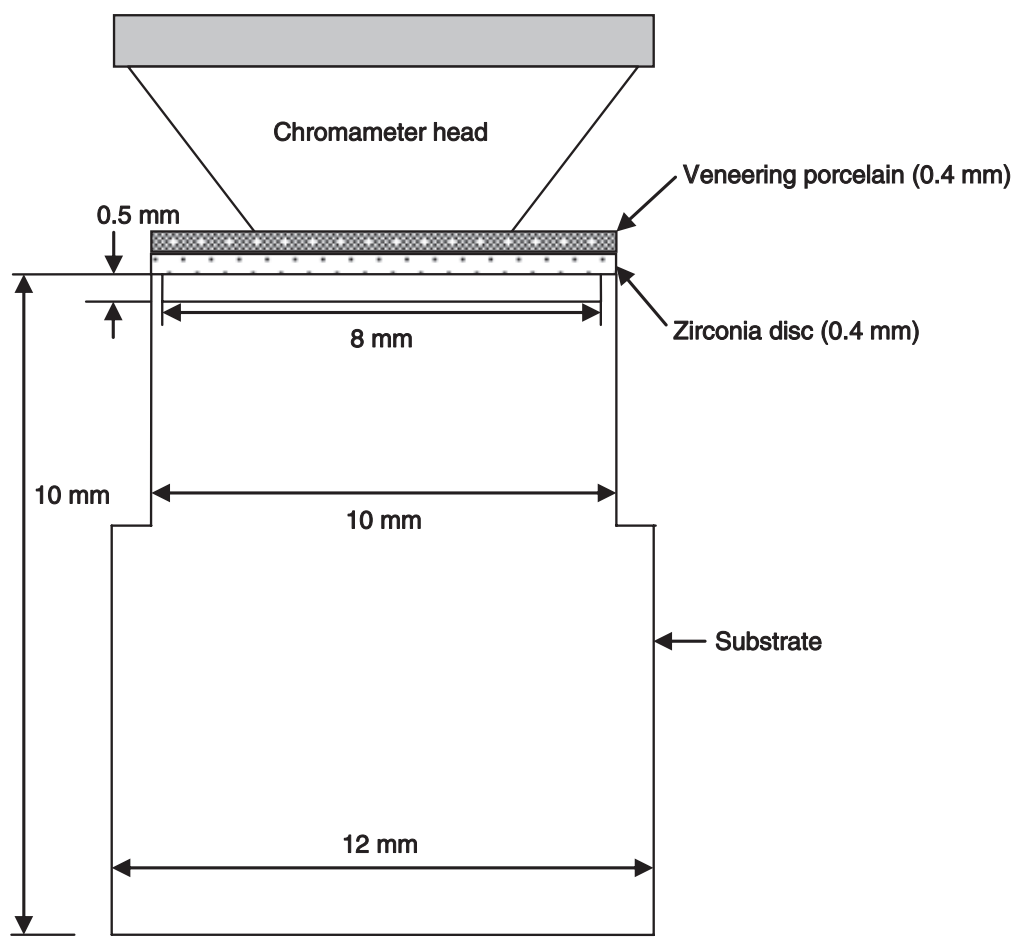

Figure 1 Specimen consisting of the substrate and a veneered zirconium oxide disc. Chromameter head in place.
(6) The substrate covered with a disc veneered with Vita shade $A 1$ porcelain $(\mathrm{S}+\mathrm{D}+\mathrm{A} 1)$ and the same substrate covered with a disc veneered with Vita shade $\mathrm{B} 4$ porcelain $(\mathrm{S}+\mathrm{D}+\mathrm{B} 4):(\mathrm{S}+\mathrm{D}+\mathrm{A} 1)-(\mathrm{S}+\mathrm{D}+\mathrm{B} 4)$.

Differences were calculated using the color coordinate measurements $\left(L^{*}, a^{*}, b^{*}\right)$ of each specimen. The total color difference $\Delta \mathrm{E}$ was obtained using the formula $\Delta \mathrm{E}=\left(\left[\mathrm{L}^{*} 1-\mathrm{L}^{*} 2\right]^{2}\right.$ $+\left[a^{*} 1-a^{*} 2\right]^{2}+\left[b^{*} 1-b^{*} 2\right]^{2) 0.5}$, where $L^{*} 1, a^{*} 1$, and $b^{*} 1$ represent "pretreatment" color coordinates of each specimen, and $L^{*} 2, a^{*} 2$, and $b^{*} 2$ represent "posttreatment" color coordinates of each specimen. ${ }^{28}$

For each group of substrates, one-way ANOVA and multiple paired $t$-test were used for the comparison of the mean values of each color coordinate $\mathrm{L}^{*}, \mathrm{a}^{*}, \mathrm{~b}^{*}$ and total color differences $(\Delta E)$ between four variances: $S, S+D, S+D+A 1$, and $\mathrm{S}+\mathrm{D}+\mathrm{B} 4$. Fisher's PLSD post hoc test was used to evaluate statistical significances for the differences of the mean values of each color coordinate $\mathrm{L}^{*}, \mathrm{a}^{*}, \mathrm{~b}^{*}$ and the total color differences $(\Delta \mathrm{E})$ between four variances. $P<0.0001$ was considered to be statistically significant.

\section{Results}

For each group of substrates, one-way ANOVA results revealed statistically significant differences $(P<0.0001)$ for the mean values of the color coordinates $\mathrm{L}^{*}, \mathrm{a}^{*}, \mathrm{~b}^{*}$ between four variances: $\mathrm{S}, \mathrm{S}+\mathrm{D}, \mathrm{S}+\mathrm{D}+\mathrm{A} 1$, and $\mathrm{S}+\mathrm{D}+\mathrm{B} 4$. An increase in $\mathrm{L}^{*}$ was noticed for groups of the black, gray, and tooth-colored substrates, and a decrease in $\mathrm{L}^{*}$ was noticed for the white substrates when the substrates were covered by plain zirconium oxide discs (Table 1). Another noticeable finding was a de-
Table 1 Means and standard deviations (SD) of color coordinates ( $L^{*}$, $\left.a^{*}, b^{*}\right)$ for each group of substrates

\begin{tabular}{|c|c|c|c|c|c|c|c|}
\hline \multirow[b]{2}{*}{ Substrate } & \multirow[b]{2}{*}{ Variance } & \multicolumn{2}{|c|}{$\mathrm{L}^{*}$} & \multicolumn{2}{|c|}{$a^{*}$} & \multicolumn{2}{|c|}{$b^{*}$} \\
\hline & & Mean & SD & Mean & SD & Mean & SD \\
\hline \multirow[t]{4}{*}{ White } & S & 92.31 & 3.33 & -7.79 & 0.19 & 0.51 & 0.33 \\
\hline & $\mathrm{S}+\mathrm{D}$ & 90.42 & 0.43 & -6.06 & 0.21 & 5.73 & 0.45 \\
\hline & $S+D+A 1$ & 80.63 & 1.29 & -5.98 & 0.28 & 11.59 & 0.97 \\
\hline & $S+D+B 4$ & 77.69 & 0.45 & -5.55 & 0.26 & 20.08 & 1.14 \\
\hline \multirow[t]{4}{*}{ Black } & S & 16.64 & 4.37 & -1.60 & 0.23 & 0.46 & 0.26 \\
\hline & $S+D$ & 85.86 & 0.50 & -5.35 & 0.20 & 5.04 & 0.47 \\
\hline & $\mathrm{S}+\mathrm{D}+\mathrm{A} 1$ & 76.42 & 1.18 & -5.50 & 0.25 & 10.16 & 0.73 \\
\hline & $S+D+B 4$ & 74.03 & 0.42 & -5.19 & 0.21 & 18.05 & 0.90 \\
\hline \multirow[t]{4}{*}{ Gray } & S & 64.58 & 0.83 & -6.20 & 0.12 & 6.23 & 0.27 \\
\hline & $S+D$ & 86.95 & 0.37 & -5.51 & 0.30 & 5.39 & 0.69 \\
\hline & $S+D+A 1$ & 77.32 & 1.15 & -5.56 & 0.25 & 10.86 & 0.78 \\
\hline & $S+D+B 4$ & 74.85 & 0.38 & -5.15 & 0.23 & 18.55 & 0.96 \\
\hline \multirow[t]{4}{*}{ Tooth-colored } & S & 69.13 & 0.84 & -6.13 & 0.09 & 10.40 & 0.84 \\
\hline & $S+D$ & 87.05 & 0.33 & -5.39 & 0.15 & 5.66 & 0.38 \\
\hline & $\mathrm{S}+\mathrm{D}+\mathrm{A} 1$ & 77.51 & 1.15 & -5.22 & 0.19 & 10.76 & 0.69 \\
\hline & $S+D+B 4$ & 75.03 & 0.42 & -5.07 & 0.29 & 18.94 & 0.75 \\
\hline
\end{tabular}

Note: where $\mathrm{S}=$ substrate, $\mathrm{S}+\mathrm{D}=$ substrate and unveneered disc, $\mathrm{S}+\mathrm{D}+\mathrm{A} 1=$ disc plus $\mathrm{A} 1$ veneering porcelain, and $\mathrm{S}+\mathrm{D}+\mathrm{B} 1=$ disc plus $\mathrm{B} 1$ veneering porcelain.

crease of the $\mathrm{L}^{*}$ and an increase of the $\mathrm{b}^{*}$ for all four groups of the substrates after the discs were veneered with Vita shade A1 or B4 porcelain. These changes of $\mathrm{L}^{*}$ and $\mathrm{b}^{*}$ were greater when the discs were veneered with shade B4 porcelain than with A1. 
Table 2 Means and SDs of total color difference $(\Delta E)$ for each group of substrates. Where $S=$ substrate, $S+D=$ substrate and unveneered disc, $\mathrm{S}+\mathrm{D}+\mathrm{A} 1=\operatorname{disc}$ plus $\mathrm{A} 1$ veneering porcelain, and $\mathrm{S}+\mathrm{D}+\mathrm{B} 1=\operatorname{disc}$ plus $\mathrm{B} 1$ veneering porcelain.

\begin{tabular}{|c|c|c|c|}
\hline Substrate & Variance & Mean $\Delta \mathrm{E}$ & SD \\
\hline \multirow[t]{6}{*}{ White } & $S-(S+D)$ & 7.61 & 0.72 \\
\hline & $S-(S+D+A 1)$ & 19.09 & 1.19 \\
\hline & $\mathrm{S}-(\mathrm{S}+\mathrm{D}+\mathrm{B} 4)$ & 26.40 & 1.04 \\
\hline & $(S+D)-(S+D+A 1)$ & 13.65 & 0.97 \\
\hline & $(S+D)-(S+D+B 4)$ & 20.57 & 1.14 \\
\hline & $(\mathrm{S}+\mathrm{D}+\mathrm{A} 1)-(\mathrm{S}+\mathrm{D}+\mathrm{B} 4)$ & 8.74 & 1.20 \\
\hline \multirow[t]{6}{*}{ Black } & $S-(S+D)$ & 67.34 & 4.49 \\
\hline & $S-(S+D+A 1)$ & 61.71 & 4.49 \\
\hline & $S-(S+D+B 4)$ & 60.38 & 3.92 \\
\hline & $(S+D)-(S+D+A 1)$ & 9.55 & 1.19 \\
\hline & $(S+D)-(S+D+B 4)$ & 16.69 & 0.92 \\
\hline & $(S+D+A 1)-(S+D+B 4)$ & 7.93 & 1.05 \\
\hline \multirow[t]{6}{*}{ Gray } & $S-(S+D)$ & 20.28 & 0.88 \\
\hline & $S-(S+D+A 1)$ & 14.54 & 1.33 \\
\hline & $S-(S+D+B 4)$ & 16.85 & 0.93 \\
\hline & $(S+D)-(S+D+A 1)$ & 9.90 & 1.31 \\
\hline & $(S+D)-(S+D+B 4)$ & 17.38 & 0.97 \\
\hline & $(S+D+A 1)-(S+D+B 4)$ & 8.15 & 1.10 \\
\hline \multirow[t]{6}{*}{ Tooth-colored } & $S-(S+D)$ & 16.30 & 1.00 \\
\hline & $S-(S+D+A 1)$ & 9.28 & 0.91 \\
\hline & $S-(S+D+B 4)$ & 11.29 & 1.04 \\
\hline & $(S+D)-(S+D+A 1)$ & 10.05 & 1.27 \\
\hline & $(S+D)-(S+D+B 4)$ & 17.54 & 0.95 \\
\hline & $(S+D+A 1)-(S+D+B 4)$ & 8.30 & 1.00 \\
\hline
\end{tabular}

No statistically significant difference was detected for the mean values of the $\mathrm{a}^{*}$ coordinate between $\mathrm{S}+\mathrm{D}$ and $\mathrm{S}+\mathrm{D}+\mathrm{A} 1$ for both white and gray substrates $(P=0.3055, P=0.5200)$. For tooth-colored (Vita shade A3) substrates, no statistically significant difference was found for the mean values of the $b^{*}$ coordinate between $\mathrm{S}$ and $\mathrm{S}+\mathrm{D}+\mathrm{A} 1(P=0.1283)$. All units of total color differences $(\triangle \mathrm{E})$ between four variances: $S, S+D$, $\mathrm{S}+\mathrm{D}+\mathrm{A} 1$, and $\mathrm{S}+\mathrm{D}+\mathrm{B} 4$ were greater than 3.7 , and there were statistically significant differences $(P<0.0001)$ of the resulting colors between $\mathrm{S}, \mathrm{S}+\mathrm{D}, \mathrm{S}+\mathrm{D}+\mathrm{A} 1$, and $\mathrm{S}+\mathrm{D}+\mathrm{B} 4$ for each group of the substrates (Table 2, Figs 1-4).

\section{Discussion}

All-ceramic crowns are now widely used for esthetic restorations of the anterior dentitions due to their lifelike appearance and long-term predictability. Zirconium oxide is currently a popular coping material of all-ceramic crowns due to its high flexural strength. ${ }^{29}$ To achieve a natural tooth-like appearance, zirconium oxide coping material veneered with feldspathic porcelain should effectively cover discoloration of underlying tooth structure or core. Models simulating discoloration of tooth structure were developed in this study. Although color measurements of tooth discoloration are not available in the literature, such teeth have been described as appearing yellow, brown, or gray to black. ${ }^{30,31}$ Therefore, the model used seems realistic for the described scenario.

After searching the refereed journals in English we could not find an article supporting the optimum amount of axial reduction for a zirconia restoration. The only references come from manufacturer recommendations, and these are not consistent. The minimum zirconia coping thickness from manufacturers is $0.4 \mathrm{~mm}$, and the minimum reduction recommended by manufacturers is $0.8 \mathrm{~mm}$. Thus, the thickness of porcelain for our study was chosen as $0.4 \mathrm{~mm} .^{32,33}$

For groups of the black, gray, and tooth-colored substrates, an increase of the $\mathrm{L}^{*}$ resulting in a shift in color toward more white when the substrates were covered by plain zirconium oxide discs can be attributed to whiteness and increasing opacity of zirconium oxide discs resulting from the addition of stabilizing oxides like $\mathrm{CaO}, \mathrm{MgO}$, and $\mathrm{Y}_{2} \mathrm{O}_{3}$ to generate partially stabilized zirconia (PSZ) of increased physical properties. ${ }^{2,29}$ Opacity is one of the primary factors in controlling esthetics of a ceramic restoration, especially when underlying discolored tooth structures or metal cores are to be restored, and is a critical consideration in selection of materials. ${ }^{19,21-25,34-36}$

For all four substrate groups, a decrease of the $\mathrm{L}^{*}$ and an increase of the $b^{*}$ after the discs were veneered with Vita shade A1 or B4 porcelain is due to the fact that porcelain of Vita shade A1 or B4 has lower value (more gray) and higher magnitude in
Figure 2 Total color differences $(\Delta E)$ for white substrates.

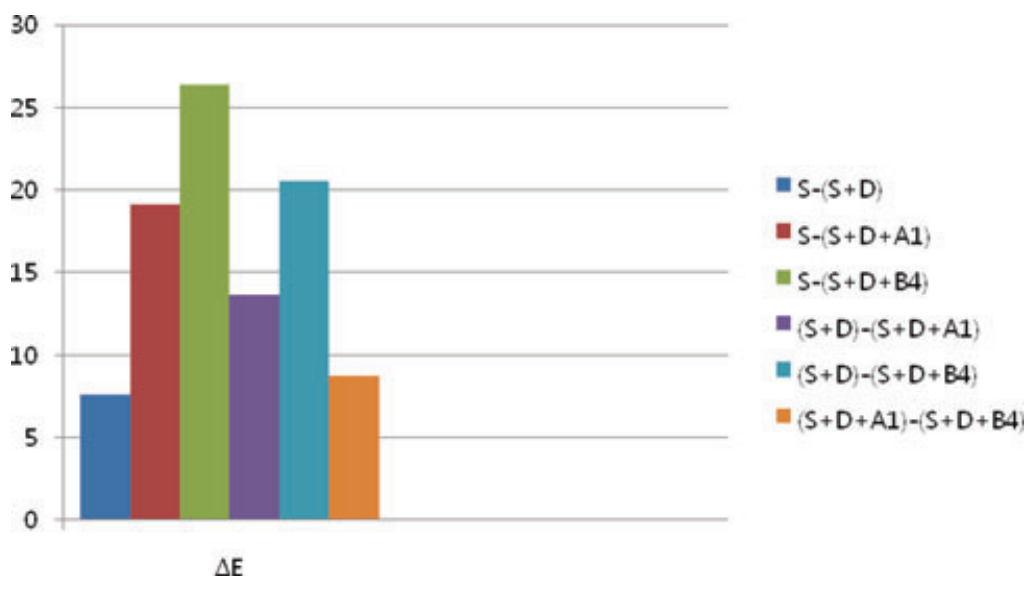




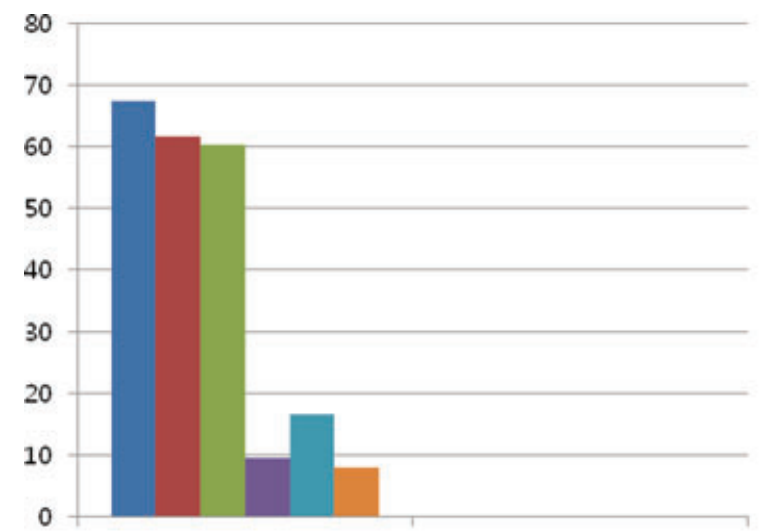

$\Delta \mathrm{E}$

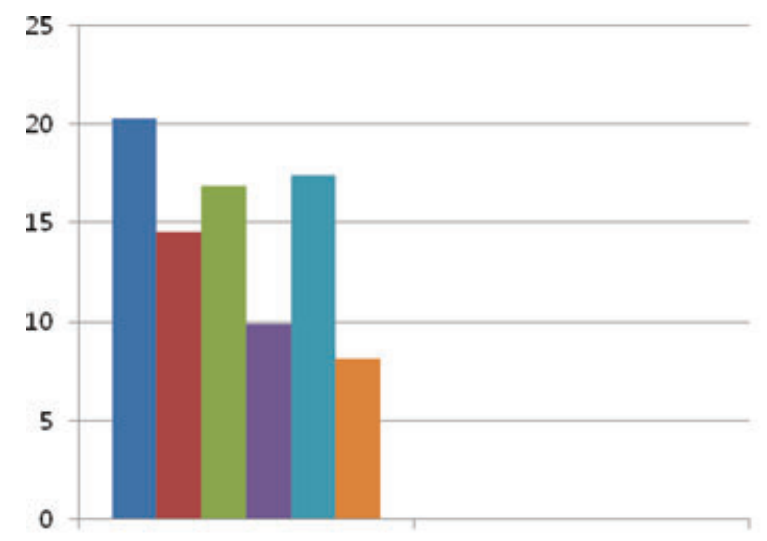

$\Delta \mathrm{E}$

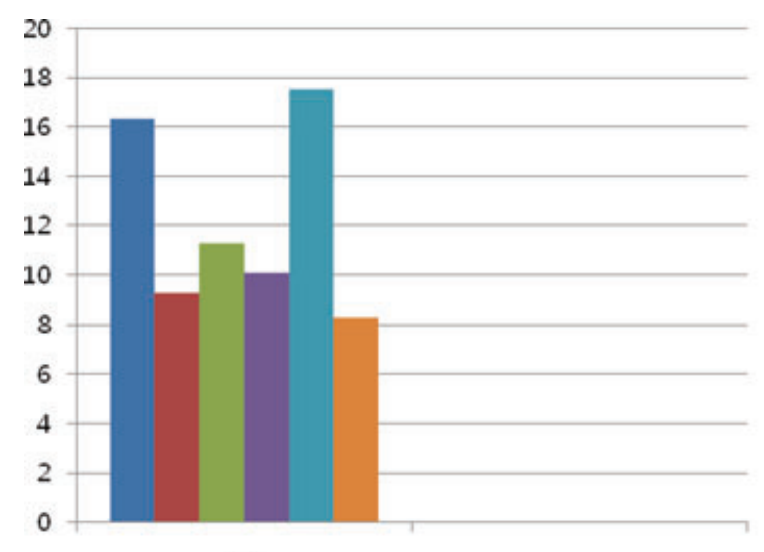

$\Delta \mathrm{E}$

$$
=\mathrm{S}-(\mathrm{S}+\mathrm{D})
$$

$=S-(S+D+A 1)$

$=S-(S+D+B 4)$

$=(S+D)-(S+D+A 1)$

$=(S+D)-(S+D+B 4)$

$=(S+D+A 1)-(S+D+B 4)$

$=\mathrm{S}-(\mathrm{S}+\mathrm{D})$

= $\mathrm{S}-(\mathrm{S}+\mathrm{D}+\mathrm{A} \mathbf{1})$

$=S-(S+D+B 4)$

$=(S+D)-(S+D+A 1)$

$=(S+D)-(S+D+B 4)$

$=(S+D+A 1)-(S+D+B 4)$

= $\mathrm{S}-(\mathrm{S}+\mathrm{D})$

= $\mathrm{S}-(\mathrm{S}+\mathrm{D}+\mathrm{A} \mathbf{1})$

$=\mathrm{S}-(\mathrm{S}+\mathrm{D}+\mathrm{B4})$

$=(S+D)-(S+D+A 1)$

$=(S+D)-(S+D+B 4)$

$=(S+D+A 1)-(S+D+B 4)$
Figure 3 Total color differences $(\Delta E)$ for black substrates.
Figure 4 Total color differences $(\Delta E)$ for gray substrates.
Figure 5 Total color differences $(\Delta \mathrm{E})$ for tooth-colored substrates. yellowness than a pure zirconium oxide disc. This result implies that a veneering porcelain of a certain shade has an effect on the modification of the final color of an all-ceramic restoration, and is in agreement with the results of previous studies. ${ }^{20,24,26}$

Total color difference $(\Delta \mathrm{E})$ is a strong indication of the color change of test objects. Johnston and Kao reported that a color difference up to $3.7 \Delta \mathrm{E}$ units between compared objects is described as an acceptable clinical shade match in dentistry. ${ }^{5}$ For all four groups of the substrates, all units of $\Delta \mathrm{E}$ between $\mathrm{S}$,
$\mathrm{S}+\mathrm{D}, \mathrm{S}+\mathrm{D}+\mathrm{A} 1$, and $\mathrm{S}+\mathrm{D}+\mathrm{B} 4$ were much greater than 3.7 or other reported limits in the present study. This result indicates that a different color can be produced after placing plain zirconium oxide discs on the substrates or veneering the discs owing to changes of the color coordinates $\left(\mathrm{L}^{*}, \mathrm{a}^{*}, \mathrm{~b}^{*}\right)$ in some or all dimensions irrespective of the initial color of the substrates. Compared with the initial color of the substrates, total color differences were greater before veneering the discs $(67.34,20.28$, 16.30) than after veneering with porcelain of shade A1 or B4 
(61.71 \& 60.38, $14.54 \& 16.85,9.28$, and 11.29) for the black, gray, and tooth-colored substrates. This finding can probably be attributed to the shade of the veneering porcelains, which decreased the value of $L^{*}$ and increased the value of $b^{*}$, resulting in a shift in color toward more gray and yellow, and this shift in color was greater after veneering the discs with shade B4 porcelain than with A1. For white substrates, the total color difference was greater after veneering the discs with porcelain of shade A1 or B4 (19.09 and 26.40) than before veneering (7.61). This may be due to the fact that the initial color of zirconium oxide discs before veneering was close to white. With respect to the results of the present study, it can be considered that interactions of the color coordinates $\left(\mathrm{L}^{*}, \mathrm{a}^{*}, \mathrm{~b}^{*}\right)$ between the substrate, zirconium oxide, and veneering porcelain have an influence on the amount of change of the initial color of the substrates, and the initial color of the substrates can be hidden or changed by putting plain zirconium oxide discs on them, and the final color of the substrates can be further modified depending on the shade of veneering porcelain. This result supports the original hypothesis of the present study.

Achieving a correct color match between natural dentition and restoration is a complex process due to the complex optical characteristics of tooth color. The management of a discolored tooth to achieve maximum esthetics is more difficult compared to that of an undiscolored tooth. ${ }^{18}$ Effective masking of the dark color of underlying structures can be achieved by increasing the amount of opaque pigments in the porcelain, the thickness of the coping or veneering material, the opacity of the luting agent, or by staining the external surface of the restorations; however, these methods sometimes may cause a lifeless and overcontoured appearance of the final restorations, unless properly manipulated. ${ }^{37-41}$ Therefore, several clinical and laboratorial factors should be considered to maximize the esthetic result of an all-ceramic system used: individual's perception of color, light source used for color evaluation, surface and structural characteristics of both the tooth and the restorative materials used, composition, translucency, and opacity of core materials, core and veneer thickness, color of supporting tooth, cement, technique of ceramic condensation, temperature and number of firing cycles, thickness of dentine ceramic, and glaze cycle.

There are some limitations of the present study. Minolta CR321 was used as a color measuring instrument. Despite its wide use for color assessment, a colorimeter does not register spectral reflectance and can be less accurate than a spectrophotometer. ${ }^{42}$ Validity of the technique used for color measurement is assured by employing a calibration process using one or more known standards and setting the instrument to give a valid measure when measuring these standards; however, given the possibility that the standard may have a different translucency than the specimen and that translucency may influence measurement error, simple calibration using only a single standard is insufficient to assure the validity of color measurements of specimens of varying translucency. ${ }^{43}$ It has been reported that the final color of the all-ceramic restorations is influenced by the color and thickness of the cement and the repeated firings. ${ }^{40,41,44,45}$ No luting agent was used, and all specimens were not submitted to repeated firings in the present study. A $0.5 \mathrm{~mm}$ space between the substrates and discs was designed for the addition of cement in future studies. Optical fluid such as distilled water for optical connection was not used. Therefore, it should be considered that as light travels through this space, an increase of scattering light would increase opacity and decrease translucency of a resulting color. ${ }^{46}$ Also, white zirconium oxide discs were used as coping materials, but zirconia substructures can be colored in 1 of 7 shades after milling. ${ }^{47}$ Manipulation of these limitations of the present study may provide a direction for further research about the masking ability of zirconium oxide as a coping material.

\section{Conclusions}

Within the limitations of the present study and the materials used, the following conclusions can be made:

1. Zirconium oxide discs alone have a degree of masking ability for the substrates of four different colors.

2. The resulting color of the substrates may be further modified with the veneering porcelain.

3. More significant changes in color were noticed in $\mathrm{L}^{*}$ and $\mathrm{b}^{*}$ coordinates than $\mathrm{a}^{*}$ coordinates when the substrates were covered by plain and veneered zirconium oxide discs.

\section{References}

1. Kelly JR, Nishimura I, Campbell SD: Ceramics in dentistry: historical roots and current perspectives. J Prosthet Dent 1996; 75:18-32

2. Kelly JR, Denry I: Stabilized zirconia as a structural ceramic: an overview. Dent Mater 2008;24:289-298

3. Studart AR, Filser F, Kocher P, et al: Cyclic fatigue in water of veneer-framework composites for all-ceramic dental bridges. Dent Mater 2007;23:115-123

4. Tinschert J, Natt G, Mautsch W, et al: Fracture resistance of lithium disilicate-, alumina-, and zirconia-based three-unit fixed partial dentures: a laboratory study. Int J Prosthodont 2001;14:231-238

5. Johnston WM, Kao EC: Assessment of appearance match by visual observation and clinical colorimetry. J Dent Res 1989;68:819-822

6. Vichi A, Ferrari M, Davidson CL: Color and opacity variations in three different resin-based composite products after water aging. Dent Mater 2004;20:530-534

7. Douglas RD, Steinhauer TJ, Wee AG: Intraoral determination of the tolerance of dentists for perceptibility and acceptability of shade mismatch. J Prosthet Dent 2007;97:200-208

8. Lindsey DT, Wee AG: Perceptibility and acceptability of CIELAB color differences in computer-simulated teeth. J Dent 2007;35:593-599

9. Ishikawa-Nagai S, Yoshida A, Sakai M, et al: Clinical evaluation of perceptibility of color differences between natural teeth and all-ceramic crowns. J Dent 2009;37(Suppl. 1):e57-63

10. Ghinea R, Perez MM, Herrera LJ, et al: Colour difference thresholds in dental ceramics. J Dent 2010;38(Suppl 2):e57-64

11. Lee Y, Yu B, Lim JI, et al: Perceived color shift of a shade guide according to the change of illuminant. J Prosthet Dent 2011;105:91-99

12. Lee YK, Lim BS, Kim CW: Difference in polymerization color changes of dental resin composites by the measuring aperture size. J Biomed Mater Res B Appl Biomater 2003;66:373-378 
13. Paravina RD, Ontiveros JC, Powers JM: Curing-dependent changes in color and translucency parameter of composite bleach shades. J Esthet Restor Dent 2002;14:158-166

14. Yu B, Lee YK: Differences in color, translucency and fluorescence between flowable and universal resin composites. J Dent 2008;36:840-846

15. Kim IJ, Lee YK: Changes in color and color parameters of dental resin composites after polymerization. J Biomed Mater Res B Appl Biomater 2007;80:541-546

16. Kim BJ, Yu B, Lee YK: Shade distribution of indirect resin composites compared with a shade guide. J Dent 2008;36:1054-1060

17. Vichi A, Louca C, Corciolani G, et al: Color related to ceramic and zirconia restorations: a review. Dent Mater 2011;27:97-108

18. Holloway JA, Miller RB: The effect of core translucency on the aesthetics of all-ceramic restorations. Pract Periodont Aesthet Dent 1995;9:567-574

19. Yaman P, Qazi SR, Dennison JB, et al: Effect of adding opaque porcelain on the final color of porcelain laminates. J Prosthet Dent 1997;77:136-140

20. Fabbri G, Mancini R, Marinelli V, et al: Anterior discolored teeth restored with procera all-ceramic restorations: a clinical evaluation of the esthetic outcome based on the thickness of the core selected. Eur J Esthet Dent 2011;6:76-86

21. Zhang F, Heydecke G, Razzoog ME: Double-layer porcelain veneers: effect of layering on resulting veneer color. J Prosthet Dent 2000;84:425-431

22. Chu FC, Chow TW, Chai J: Contrast ratios and masking ability of three types of ceramic veneers. J Prosthet Dent 2007;98:359-364

23. Chen YM, Smales RJ, Yip KH, et al: Translucency and biaxial flexural strength of four ceramic core materials. Dent Mater 2008;24:1506-1511

24. Lee Y, Cha H, Ahn J: Layered color of all-ceramic core and veneer ceramics. J Prosthet Dent 2007;97:279-286

25. Heffernan MJ, Aquilino SA, Diaz-Arnold AM, et al: Relative translucency of six all-ceramic systems. Part I: core materials. J Prosthet Dent 2002;88:4-9

26. Heffernan MJ, Aquilino SA, Diaz-Arnold AM, et al: Relative translucency of six all-ceramic systems. Part II: core and veneer materials. J Prosthet Dent 2002;88:10-15

27. Kishta-Derani M, Neiva G, Yaman P: In vitro evaluation of tooth-color change using four paint-on tooth whiteners. Oper Dent 2007;32:394-398

28. Hunter RS, Harold RW: The Measure of Appearance (ed 2). New York, Wiley, 1987, pp. 178-185

29. Guazzato M, Proos K, Quach L, et al: Strength, reliability, and mode of fracture of bilayered porcelain/zirconia (Y-TZP) dental ceramics. Biomaterials 2004;25:5045-5052

30. Joiner A: Tooth colour: a review of the literature. J Dent 2004;32:3-12
31. Weinstein SP: Classification of clinical attributes in tooth appearance. Pract Proced Aesthet Dent 2008;3:143-151

32. Blatz M, Ferencz J, Holst S, et al: Handling guidelines for Nobel Procera zirconia copings and frameworks. Available at: http:// www.dentalteam.fi/Handling\%20Zirconia\%20rev\%2010.pdf. Accessed May 1, 2009

33. Procera Preparation Guide. Available at: http://www. kuwatapandent.com/pdf/services_page/Procera_PrepaCement_ GB_C7_tcm57-9426.pdf. Accessed July 19, 2012

34. Rasetto FH, Driscoll CF, Prestipino V, et al: Light transmission through all-ceramic dental materials: a pilot study. J Prosthet Dent2004;91:441-446

35. Ozcelik TB, Yilmaz B, Ozcan I, et al: Colorimetric analysis of opaque porcelain fired to different base metal alloys used in metal ceramic restorations. J Prosthet Dent 2008;9:193-202

36. Raptis NV, Michalakis KX, Hirayama H: Optical behavior of current ceramic systems. Int J Periodontics Restorative Dent 2006;26:31-41

37. Kohal RJ, Pelz K, Strub JR: Effect of different crown contours on periodontal health in dogs. Microbiological results. J Dent 2004;32:153-159

38. Mclnnes-Lesoux PM, Zinck JH, Weinberg R: The effectiveness of opaque and color modifier materials. A laboratory study. J Am Dent Assoc 1987;114:205-209

39. Corciolani G, Vichi A, Louca C, et al: Influence of layering thickness on the color parameters of a ceramic system. Dent Mater 2010;26:737-742

40. Chang J, Da Silva JD, Sakai M, et al: The optical effect of composite luting cement on all ceramic crowns. J Dent 2009;37:937-943

41. Fazi G, Vichi A, Ferrari M: Influence of four different cements on the color of zirconia structures of varying ceramic thickness. Int Dent SA 2006;8:20-26

42. Kim-Pusateri S, Brewer J, Davis EL, et al: Reliability and accuracy of four dental shade-matching devices. J Prosthet Dent 2009;101:93-99

43. Johnston WM: Color measurement in dentistry. J Dent 2009;37(Suppl 1):e2-6

44. Vichi A, Ferrari M, Davidson CL: Influence of ceramic and cement thickness on the masking of various types of opaque posts. J Prosthet Dent 2000;83:412-417

45. Pires-de-Souza Fde C, Casemiro LA, Garcia Lda F, et al: Color stability of dental ceramics submitted to artificial accelerated aging after repeated firings. J Prosthet Dent 2009;101: 13-18

46. O'Brien WJ: Double layer effect and other optical phenomena related to esthetics. Dent Clin North Am 1985;29:667-672

47. Piwowarczyk A, Ottl P, Lauer HC, et al: A clinical report and overview of scientific studies and clinical procedures conducted on the 3M ESPE Lava All-Ceramic System. J Prosthodont 2005; $14: 39-45$ 